\title{
THE BARRAQUER OPERATION FOR CATARACT
}

Lieut.-Colonel Henry Smith, C.I.E., I.M.S. (retd.)

LONDON

I HAD the pleasure of seeing Dr. Barraquer operate in his own clinic at Barcelona in the spring of this year. His instrument acted beautifully. During my recent tour over the northern half of the American Continent, I saw it used by several excellent operators. We came to some very definite conclusions about the instrument and the use of it.

The principle of this instrument, raising a vacuum to a given tension and maintaining it at that tension without exceeding it, is perfect.

A Bunsen pump will do the same thing and will do it nearly as well. The great weakness of the instrument is that the valve is in the hand piece. This necessitates bringing the muscles of the forearm strongly into action, and maintaining that action in keeping the valve closed. This causes the operator to have a stiff wrist and to use the muscles of his forearm in performing the operation, whereas not a single muscle of the forearm should ever be used in a cataract operation. The muscles of the hand, alone, should be used if we wish to have the necessary lightness of touch and dexterity.

The valve should be foot controlled, not hand controlled: Th can be done by putting a metallic tube $A-B$ in the middle of the rubber tube into which leads another open ended rubber tube $C-D$. The tube $\mathrm{C}-\mathrm{D}$ can squeezing it under method would be to tube with the foot vacuum spoon should shank and light, and ten o'clock in the then be closed by the foot. A simpler squeeze the stout on the ground. The be straight in the should be put in at right eye and at two o'clock in the left eye, and not passed in over the forehead. The lens can then be dislocated by rolling the instrument between the thumb and index and middle fingers. If on the other hand it is passed in over the brow, the muscles of the forearm inevitably come into play in levering it out.

The chief thing which stimulates me to write this article is that I have heard complaints of an undue number of cases of detachment of the retina after the use of this instrument.

I am very anxious to assist any one who is trying to extract cataract in the capsule by any method.

If it is realized that the mechanics of this operation and of the one I have worked out are exactly the same, and the knowledge 
properly applied, then we will hear less of such trouble as detachment of the retina.

In my method we put pressure on the lower third of the lens through the cornea and continue that pressure throughout at right angles to the anterior surface of the lens as it emerges. This causes the lens to swing round on its transverse axis. The suspensory ligament is thus ruptured first opposite the middle of the wound. The Barraquer instrument should grip the front of the lens and then be rolled between the fingers so as to do exactly the same thing. As used by some operators when it gets its grip it is made simply to lift forward the lens. By this means a temporary vacuum is produced behind the lens which ipso facto lifts forward the vitreous body, and hence dislocation of the retina or even of the choroid. When, however, it is made to roll on its transverse axis so as to rupture the suspensory ligament at the wound first, then air passes behind the lens and no such vacuum lifting the whole contents of the eye forward comes into action. This is the essential point to keep in mind when using this instrument. As to the range of adaptability of this instrument, it is not suitable for Morgagnian cataracts or cataracts with an easily ruptured capsule. On the other hand, such cases are as easily extracted by my method as any other class.

\section{BILATERAL CHANGES IN THE CORNEAE BY \\ Professor Gian Luigi Colombo, PARMA} FOLLOWING EXPOSURE TO COLD IN AN AIRMAN*

AIUTO E LIB. DOCENTE IN THE ROYAL UNIVERSITY OPHTHALMIC CLINIC, PARMA, DIR. PROF. C. GALLENGA

THE lesion here described occurred in exceptional circumstances and is of considerable interest as it is probably unique in ocular pathology.

An airman officer, V. V., of Messina, 23 years of age, started for an aerial expedition from a mountainous zone in April, 1917. After about an hour of flight he lost the left glass of his protecting spectacles, and two hours later lost the other glass as well. The aeroplane reached and maintained the height of 4,500 metres over mountainous country which was covered with snow. The airman stated that as soon as the left eye was exposed he felt a strong sensation of cold accompanied by lacrimation which, however, only lasted a short time. He had considerable difficulty in keeping the eyes open at first, but later could do so easily. The lacrimation

\footnotetext{
* From Pathologica, N 155.
} 